\title{
EXPOSURE CHAMBER MEASUREMENTS OF MASS TRANSFER AND PARTITIONING AT THE
}

PLANT/AIR INTERFACE

\author{
Randy L. Maddalena ${ }^{1 *}$, Thomas E. McKone ${ }^{1,2}$ and Norman Y. Kado ${ }^{3}$
}

1. Environmental Energy Technologies Division, Ernest Orlando Lawrence Berkeley National Laboratory, 1 Cyclotron Road, Berkeley, California, 94720, USA

2. Environmental Health Sciences, School of Public Health, University of California, Berkeley, California, 942720

3. Environmental Toxicology, One Shields Avenue, University of California, Davis, California, 95616

Abbreviated title: Measuring leaf-air intermedia transfer factors

\author{
Please send correspondence to: Randy L. Maddalena \\ Indoor Environment Program \\ Lawrence Berkeley National Laboratory \\ 1 Cyclotron Road (mail stop 90-3058) \\ Berkeley, California, 94720, USA \\ rlmaddalena@1bl.gov \\ Phone: 209) 962-5680 \\ Fax: 510) 486-6658
}




\begin{abstract}
Dynamic measures of air and vegetation concentrations in an exposure chamber and a two-box mass balance model are used to quantify factors that control the rate and extent of chemical partitioning between vegetation and the atmosphere. A continuous stirred flow-through exposure chamber was used to investigate the gas-phase transfer of pollutants between air and plants. A probabilistic two-compartment mass-balance model of plant/air exchange within the exposure chamber was developed and used with measured concentrations from the chamber to simultaneously evaluate partitioning $\left(K_{p a}\right)$, overall mass transfer across the plant/air interface $\left(U_{p a}\right)$ and loss rates in the atmosphere $\left(R_{a}\right)$ and aboveground vegetation $\left(R_{p}\right)$. The approach is demonstrated using mature Capsicum annuum (bell pepper) plants exposed to phenanthrene $(\mathrm{PH})$, anthracene (AN), fluoranthene (FL) and pyrene (PY). Measured values of $\log K_{p a}$ $\left(\mathrm{V}_{\text {[air] }} / \mathrm{V}_{\text {[fresh plant] }}\right)$ were 5.7, 5.7, 6.0 and 6.2 for PH, AN, FL and PY, respectively. Values of $U_{p a}$ $\left(\mathrm{m} \mathrm{d}^{-1}\right)$ under the conditions of this study ranged from 42 for PH to 119 for FL. After correcting for wall effects, the estimated reaction half-lives in air were 3, 9 and 25 hours for AN, FL and PY. Reaction half-lives in the plant compartment were 17, 6, 17 and 5 days for PH, AN, FL and PY. The combined use of exposure chamber measurements and models provides a robust tool for simultaneously measuring several different transfer factors that are important for modeling the uptake of pollutants into vegetation.
\end{abstract}

Key Words: Multimedia models, gas-phase plant/air exchange kinetics, semi-volatile organic chemical 


\section{Introduction}

It has long been recognized that vegetation can accumulate pollutants from other environmental compartments $(1,2)$. However, the role of terrestrial vegetation in controlling the environmental fate of pollutants has not been well characterized. As a result, including a plant compartment in mass balance calculations to predict environmental fate and the potential for exposures through the food chain remains highly uncertain. Although a large number of models have been proposed (3-14), a better understanding of the transfer factors that link the soil/plant/atmosphere continuum is required before a reliable plant module can be incorporated into exposure models.

Field studies have revealed for a range of semivolatile organic chemicals (SOC) that gas-phase transfer from the atmosphere is the dominant pathway for uptake of pollutants into aboveground vegetation $(11,15-17)$. Field studies have also been used to estimate plant/atmosphere partition coefficients $(16,18-20)$. However, competing pathways, a large number of environmental variables and the overall complexity of the soil/plant/air system make it difficult to use field studies alone to directly measure the kinetic and the thermodynamic factors controlling pollutant uptake into plants. We propose that reliable information about thermodynamic partitioning and mass transfer across the plant/air interface can be measured using controlled environmental chamber studies.

Several types of exposure chambers have been used to isolate and measure the pathway-specific uptake of various pollutants from soil and air into plants. Batch type reactors and small flow-through chambers have been used for laboratory investigations of chemical uptake in seedlings $(6,21-23)$. Larger glass chambers equipped with mixing fans have been used to measure the transfer of several gas-phase pollutants into leafs (21) and to investigate the relationship between plant uptake and chemical properties (24). Welsh-Pausch et al., (15) used a system of glass houses to investigate uptake of ambient SOCs into grass. Stirred chambers have been used to investigate the fate of volatile $(25,26)$ and semi-volatile air pollutants $(10)$ and 
open top chambers have been developed to study the effect of trace atmospheric pollutants on trees and agricultural crops (27).

Of the various chamber designs that we reviewed, the stirred chamber provides the best characteristics for controlled exposure experiments with SOCs and plants. This type of exposure system is based on a chamber design commonly referred to as the Continuous Stirred Tank Reactor (CSTR). CSTRs were originally developed for chemical engineering applications and later for plant exposure studies to evaluate the toxicity and/or fate of both gas-phase $(26,28,29)$ and aqueous pollutants (25).

This paper describes and demonstrates the mathematical and physical characteristics of a CSTR designed to expose above ground vegetation to gas-phase SOCs. An analytical solution to a two-box mass balance model is used to describe the relationship between a controlled source and the time-varying concentrations in both the chamber air and the exposed plant. The approach makes it possible to use simultaneous measurements of the dynamic concentration in both the air and the plant during and after an exposure event. This provides sufficient degrees of freedom to estimate a number of important factors including the plant/air partition coefficient, the mass transfer rate across the plant/air interface and transformation or loss rates in both the plant and air.

\section{Mathematical Background on Chemical Dynamics in Exposure Chambers}

A number of exposure chamber studies have reported plant/air partition coefficients (10, 21, 23, 24, 30). However, with the exception of Hauk et al. (10), these studies focus primarily on estimating the plant/air partition coefficient using a method originally described in Bacci et al. (21). Hauk et al. (10) extended the approach to develop and calibrate a two-compartment needle model and reported both fugacity-based conductivities and volume adjusted fugacity capacities.

A key and novel step to our approach is the use of measured source strength and dynamic concentrations in both the air and the plant together with models to simultaneously characterize multiple factors of pollutant fate in the plant/air system. These include the plant/air partition 
coefficient, $K_{p a}\left(\mathrm{~m}^{-3}\right.$ air $/ \mathrm{m}^{-3}$ fresh plant $)$, the overall mass transfer coefficient for the plant/air interface, $U_{p a}\left(\mathrm{~m} \mathrm{~d}^{-1}\right)$ and the first-order reaction rate constants in air, $R_{a}\left(\mathrm{~d}^{-1}\right)$ and aboveground vegetation, $R_{p}\left(\mathrm{~d}^{-1}\right)$. The overall mass balance for the exposure chamber is written as a system of first-order linear inhomogeneous differential equations where the time dependent concentration in the air compartment is

$$
\frac{d C_{a}}{d t}=\frac{S_{a}}{V_{c}}-\left(\frac{R_{a} V_{c}+f+U_{p a} A_{p a}}{V_{c}}\right) C_{a}+\left(\frac{U_{p a} A_{p a}}{K_{p a} V_{c}}\right) C_{p},
$$

and the time dependent concentration in the plant compartment is

$$
\frac{d C_{p}}{d t}=\frac{S_{p}}{V_{p}}+\left(\frac{U_{p a} A_{p a}}{V_{p}}\right) C_{a}-\left(\frac{U_{p a} A_{p a} / K_{p a}+\left(R_{p}+G_{p}\right) V_{p}}{V_{p}}\right) C_{p} .
$$

The subscripts $a, p$ and $c$ refer to the air, plant and overall chamber compartments, respectively, $C_{i}$ is the concentration in each compartment $\left(\mathrm{mol} \mathrm{m}^{-3}\right), S_{i}$ are the source terms $\left(\mathrm{mol} \mathrm{d}^{-1}\right), V_{i}$ are the volumes $\left(\mathrm{m}^{3}\right), R_{i}$ are the first-order reaction rates $\left(\mathrm{d}^{-1}\right), A_{p a}$ is the interfacial area between the air and plant $\left(\mathrm{m}^{2}\right), f$ is the flow rate of air through the chamber $\left(\mathrm{m}^{3} \mathrm{~d}^{-1}\right), G_{p}$ is the growth dilution rate $\left(\mathrm{d}^{-1}\right)$, and $U_{p a}$ is the overall mass transfer coefficient across the plant/air interface $\left(\mathrm{m} \mathrm{d}^{-1}\right)$.

Pollutant transfer from the above ground plant parts through the stem to the root and soil is assumed to be negligible for compounds with $\log$ Kow $>4$ (31). In addition, the chamber is designed to limit the direct transfer of pollutant between the air and soil. Therefore, exchange processes between the above- and below-ground plant parts are excluded from the model.

Equations 1 and 2 can be rewritten in the form of a system of coupled first-order differential equations ((32) page 570) such that eq 1 becomes

$$
\frac{d y_{1}}{d t}=J_{1}-k_{11} y_{1}+k_{12} y_{2}
$$

and eq 2 becomes

$$
\frac{d y_{2}}{d t}=J_{2}+k_{21} y_{1}-k_{22} y_{2}
$$

where $J_{i}$ are the volume normalized source terms $\left(\mathrm{mol} \mathrm{m}^{-3} \mathrm{~d}^{-1}\right), y_{i}$ are the concentrations 
$\left(\mathrm{mol} \mathrm{m}{ }_{[\text {fresh] }}^{-3}\right.$ and $k_{i j}$ are the overall rate constants for transfer and transformation $\left(\mathrm{d}^{-1}\right)$.

For a multi-phased exposure event (i.e., uptake- and clearance-phase), the start time ( $t=$ $\left.t^{*}\right)$ for each phase is defined as $t^{*}=t_{(1)}, t_{(2)}, \ldots t_{(n)}$, where $t_{(1)}, t_{(2)}, \ldots t_{(n)}$, are the times when the source undergoes a step increase or decrease and $n$ is the total number of phases in the experiment. The initial concentrations in each compartment at the beginning of each phase are designated $y_{i}^{*}$ and each rectangular (i.e., constant) source term, defined as $J_{i}^{*}$, applies to the duration of the phase beginning at time $t=t^{*}$. Given $t, t^{*}, y_{i}^{*}$ and $J_{i}^{*}$ for each phase of the exposure event, a general analytical solution for the time dependent concentrations in air, $y_{l}(t)$, is

$$
\begin{aligned}
& y_{1}(t)=\frac{\exp \left[-g_{2}\left(t-t^{*}\right)\right]-\exp \left[-g_{1}\left(t-t^{*}\right)\right]}{g g_{12}} \times\left(k_{12} y_{2}^{*}-k_{11} y_{1}^{*}\right) \\
& +\frac{g_{1} \exp \left[-g_{2}\left(t-t^{*}\right)\right]-g_{2} \exp \left[-g_{1}\left(t-t^{*}\right)\right]}{g g_{12}} \times y_{1}^{*} \\
& +\left\{\frac{\frac{1-\exp \left[-g_{2}\left(t-t^{*}\right)\right]}{g_{2}}-\frac{1-\exp \left[-g_{1}\left(t-t^{*}\right)\right]}{g_{1}}}{g g_{12}}\right\} \times\left(k_{12} J_{2}^{*}-k_{11} J_{1}^{*}\right) \\
& +\left\{\frac{\frac{1-\exp \left[-g_{2}\left(t-t^{*}\right)\right]}{g_{2} / g_{1}}-\frac{1-\exp \left[-g_{1}\left(t-t^{*}\right)\right]}{g_{1} / g_{2}}}{g g_{12}}\right\} \times J_{1}^{*}
\end{aligned}
$$

and the time dependent concentration in the plant compartment, $y_{2}(t)$, is

$$
y_{2}(t)=\frac{\exp \left[-g_{2}\left(t-t^{*}\right)\right]-\exp \left[g_{1}\left(t-t^{*}\right)\right]}{g g_{12}} \times\left(k_{21} y_{1}^{*}-k_{22} y_{2}^{*}\right)
$$




$$
+\frac{g_{1} \exp \left[-g_{2}\left(t-t^{*}\right)\right]-g_{2} \exp \left[-g_{1}\left(t-t^{*}\right)\right]}{g g_{12}} \times y_{2}^{*}
$$

$$
\begin{aligned}
& +\left\{\frac{\frac{1-\exp \left[-g_{2}\left(t-t^{*}\right)\right.}{g_{2}}-\frac{1-\exp \left[-g_{1}\left(t-t^{*}\right)\right.}{g_{1}}}{g g_{12}}\right\} \times\left(k_{21} J_{1}^{*}-k_{22} J_{2}^{*}\right) \\
& +\left\{\frac{\frac{1-\exp \left[-g_{2}\left(t-t^{*}\right)\right.}{g_{2} / g_{1}}-\frac{1-\exp \left[-g_{1}\left(t-t^{*}\right)\right.}{g_{1} / g_{2}}}{g g_{12}}\right\} \times J_{2}^{*}
\end{aligned}
$$

where the overall rate constants, $k_{i j}\left(\mathrm{~d}^{-1}\right)$ and Eigenvalues in eqs 3-6 are defined in Table 1.

This system of equations, which is easily written into a spreadsheet, describes multiple phases of an exposure event using eleven independent variables. Although the exposure scenario used in this study includes only two phases (uptake and clearance), eqs 5 and 6 can be used with any number of phases given an estimate of a constant source term for each phase. Of the eleven independent variables in the mass balance, all but four are known (i.e., either controlled or can be measured). The four unknown variables $K_{p a}, U_{p a}, R_{a}$ and $R_{p}$ are estimated by simultaneously fitting eqs 5 and 6 to the concentration time series measured during the exposure event. These two equations and two time periods (an exposure period followed by a non-exposure period) result in four equations incorporating the four unknown variables. We altered the values of the variables so as to optimize the fit of model results to observations. This process provides a set of optimum values and value ranges for the unknown variables.

\section{Physical Description and Characterization of the Exposure Chamber}

The exposure chamber used in this work is patterned after a "Continuous Stirred Tank Reactor" developed and used by the USDA $(26,29)$. A key advantage of the CSTR is that the 
exposure conditions can be controlled and monitored with a high degree of precision and the system can be built large enough to accommodate mature plants for relatively long exposure periods. These attributes make it possible to design exposure events with concentrations near those that are actually experienced in the environment and to simultaneously track the concentration changes in both the air and the plant throughout an exposure event.

The system consists of a 450-liter cylindrical exposure chamber constructed from Teflon top and bottom plates connected with eight Teflon-coated ribs and wrapped with a transparent Tedlar film. The bottom plate of the chamber is split to allow assembly around the base of a mature plant, separating the atmosphere and aboveground parts of the plant from the soil and roots. A sleeve is built into the chamber wall to allow access to the inside of the chamber for collection of plant samples. The exposure chamber is housed in a Conviron model PGR15 controlled environment room (CER). The CER is equipped with 8 Metal Halide lamps, 6 Mercury Vapor lamps and 8 incandescent (60 watt) lights producing $\sim 400$ PAR (photosynthetically active radiation; $\mu \mathrm{mol} \mathrm{m} \mathrm{m}^{-2} \mathrm{~s}^{-1}$, as photon flux density) measured at one meter below the light barrier. The CER is part of the Controlled Environment Facility at the University of California, Davis (http://greenhouse.ucdavis.edu/cef info.htm).

Room air enters the CER through polyurethane foam (PUF). Temperature, humidity, day/night cycle and light intensity are programmed using a CMP4030 Touch Screen Controller that comes standard with the CER. Air from the CER then enters the exposure chamber through a pair of $38 \mathrm{~mm}$ diameter $\times 95 \mathrm{~mm}$ long Teflon inlet cartridges (Savillex Corp.) mounted in the top plate of the chamber. The inlet cartridges are fitted with removable PUF plugs to provide (on/off) control of background levels of gas-phase pollutants entering the chamber. The top of the chamber is also fitted with a thermally controlled gas-phase generator cartridge containing glass beads coated with the chemical(s) of interest. When turned on, a controlled stream of $\mathrm{N}_{2}$ $\left(75 \mathrm{cc} \mathrm{min}^{-1}\right)$ flows through the gas-phase generator cartridge, which is heated to a constant temperature, providing a continuous source of test chemical into the chamber over an extended 
period.

No attempt was made during the exposure phase of the experiment to exclude ambient pollutant from entering the chamber. Rather, the background levels of target chemicals were monitored during the exposure event using an air-sampling cartridge (same as the inlet cartridge) fitted with PUF and mounted near the exposure chamber inlets. So the total source to the chamber during the exposure phase includes both background levels of pollutant entering the chamber and gas-phase pollutant generated by the source cartridge.

Two additional sampling cartridges containing PUF are located at the exit ports in the bottom of the chamber to monitor exposure concentrations. An elliptical three-way switching valve is installed inline between the sample cartridges at the base of the chamber and a 3/4 HP rotary vane pump. The switching valve is used to direct airflow through alternating cartridges allowing collection of air samples without disrupting flow through the system.

Flow of the single-pass air stream through the exposure chamber is monitored and controlled using a direct read rotometer. Mixing of the chamber atmosphere is maintained using both a high flow rate of air ( $\sim 10$ air changes per hour $)$ and a six-bladed stainless steel impeller turning at $300 \mathrm{rpm}$ and mounted at the top of the exposure chamber. Further details of the CER and exposure chamber are provided elsewhere (33).

\section{Chamber Characterization}

Atmospheric mixing in the exposure chamber was initially tested using measurements of the steady-state concentration of a tracer gas (benzene) collected in triplicate from 10 different locations within the chamber including the exit port. The test was performed both with the access sleeve in the chamber wall open (simulating a vegetation sampling event) and closed. The coefficient of variation $(\mathrm{CV})$ for the measured concentrations at various locations within the chamber was less than 0.02. Mixing was also tested during the actual exposure events (described later) by collecting duplicate and triplicate leaf samples at various time points from different locations within the chamber. The resulting $C V$ for measured concentrations in the leaf material 
were $0.15,0.13,0.25$ and 0.15 for phenanthrene, anthracene, fluoranthene and pyrene, respectively, with no noticeable trend or gradient in concentrations. The low $C V$ for concentrations in the empty chamber and for replicate plant samples collected from different locations on an exposed plant demonstrates adequate mixing.

Light intensity during the "daylight hours" was measured inside the exposure chamber using a hand held LI-COR Photometer (model LI-189). Duplicate measurements taken at nine different locations within the chamber gave an average PAR of $219 \pm 9 \%\left(\mu \mathrm{mol} \mathrm{m} \mathrm{m}^{-2} \mathrm{~s}^{-1}\right)$ with a slight gradient from top to bottom. Although the light intensity inside the exposure chamber was less than that measured in the CER $\left(416 \mu \mathrm{mol} \mathrm{m} \mathrm{m}^{-2} \mathrm{~s}^{-1}\right)$, the lighting was adequate for growing healthy plants. The reduction in light intensity within the exposure chamber was likely due to shadowing from the opaque Teflon top plate and less than perfect transparency of the Tedlar chamber walls. The actual light spectrum within the exposure chamber was not determined. Accounting for chamber wall effects

Even when inert materials are used to construct an exposure chamber, gas-phase chemicals interact with surfaces. This interaction can influence the fate of chemicals in a chamber and should be considered in the mass balance - particularly for semivolatile chemicals. The use of air sampling bags and canisters has led to research of sorption/desorption behavior for VOCs on inert surfaces (e.g., Tedlar, Teflon and stainless steel) (34) but few studies have attempted to characterize this interaction for SOCs. The models that are available for describing the surface interaction of SOCs are limited to only a few chemical/surface combination (35). Although adding a third compartment accounting for wall effects in the mass balance is technically appealing and theoretically justified the extra complexity cannot be supported experimentally with measured data. Therefore, to account for wall effects without significantly increasing the complexity of the mass balance, we combine the air and surface compartments into a single "chamber" compartment with an effective volume, $\left(V_{c}\right)$ that exceeds the actual volume of the chamber. 
The $V_{c}$ is similar in principle to the "apparent volume of distribution" commonly used in physiologically based pharmacokinetic modeling ((36), page 228). It is defined here as the volume of "chamber" (air plus wall) in which the chemical is distributed at a concentration equal to that observed in the gas-phase of the chamber air. We estimate the chemical-specific $V_{c}$ using a one-box mass balance for a well mixed chamber assuming that exchange between the chamber air and wall is fast relative to the residence time. Given a specified set of chamber conditions, (i.e., temperature, air flow rate, light intensity and test chemical), the $V_{c}$ can be estimated by fitting

$$
C_{a(t)}=C_{i n}+\left[C_{a}^{*}-C_{i n}\right] \exp ^{-\left(f / V_{c}\right)\left(t-t^{*}\right)}
$$

to the concentration time series profile in the exposure chamber where $C_{a(t)}\left(\mathrm{ng} \mathrm{m}^{-3}\right)$ is the measured concentration at time $=t, C_{i n}\left(\mathrm{ng} \mathrm{m}^{-3}\right)$ is the concentration in air flowing into the chamber at a flow rate $f\left(\mathrm{~m}^{3} \mathrm{~d}^{-1}\right)$ and $C^{*}{ }_{a}\left(\mathrm{ng} \mathrm{m}^{-3}\right)$ is the concentration in the chamber air when $t^{*}$ $=0$, time $_{1}$, time $_{2}, \ldots$ time $_{\mathrm{n}}$, where time 1, time $_{2}, \ldots$, time $_{\mathrm{n}}$ are the times when $C_{\text {in }}$ undergoes a step increase or decrease (26). Using the exposure scenario described in the following section and the resulting time concentration profiles shown in Fig 1, we estimate $V_{c} \pm$ sd for PH, AN, FL and PY to be $16 \pm 14,19 \pm 11,77 \pm 30$ and $82 \pm 23 \mathrm{~m}^{3}$, respectively.

\section{Exposure Chamber Experiments}

The plant exposure system described above was used to measure the gas-phase plant/air transfer factors of a set of PAHs including phenanthrene (PH), anthracene (AN), flouranthene (FL) and pyrene (PY) in mature Capsicum annuum (Yolo Wonder Bell Pepper). PAHs are included in the U.S. EPA's list of air toxics as "polycyclic organic matter" (37) and generally considered to be important environmental pollutants that warrant further study to better characterize source-to-dose relationships, particularly with respect to exposure through crops and foods. PAHs are also useful experimentally because chemicals in this class have a wide range of physicochemical properties. The range of properties is useful when investigating or developing various QSAR models. The exposure scenario described in this section is limited in scope to four 
semivolatile PAHs that are predominantly found in the gas-phase. Future work will expand the evaluation to other PAHs.

\section{Materials and Methods}

Chemicals. HPLC-grade methanol, acetone and hexane were obtained from Fisher Scientific. Dichloromethane (DCM, Omnisolve) was obtained from EM Science. Standard Reference Material 2260, Aromatic Hydrocarbons in Toluene from the National Institute of Standards and Technology (NIST, Gaithersburg, MD) was used to quantify the samples. Deuterated standards including anthracene-d10, fluoranthene-d10 and pyrene-d10, were obtained from Cambridge Isotopes (Andover, MA). Phenanthrene-d10, was from AccuStandard (New Haven, CT).

Plants. Capsicum annuum plants (Yolo Wonder bell pepper) were purchased at a local nursery and transplanted into one-gallon pots (two plants per pot) and placed in a controlled environment growth room (CER) until ready for use. The plants were watered daily with nutrient solution. The day/night cycle was programmed to 12 hours light and 12 hours dark. Mature plants were used 6-8 weeks after transplanting.

The dry/wet mass ratio $(0.11 \pm 7.6 \%)$ and extractable lipid/wet mass ratio $(0.007 \pm 19 \%)$ for the test plants were determined using the method described by Simonich and Hites (16). The one-sided leaf surface area per wet mass ratio $\left(4.23 \pm 8.6 \%\left(\mathrm{~m}^{2} \mathrm{~kg}^{-1}\right.\right.$ fresh $\left.)\right)$ was determined as in McCrady (38) and the density of the plant $\left(713 \pm 3.9 \%\left(\mathrm{~kg} \mathrm{~m}^{-3}\right.\right.$ fresh $\left.)\right)$ was determined using a water displacement method.

Air sampling and workup. The exposure chamber air and the background air entering the chamber were collected on pre-cleaned PUF plugs loaded into $4.7 \mathrm{~cm}$ O.D. $\times 12.1 \mathrm{~cm}$ Teflon sample-train segments (Savillex Corp.). The sample cartridges were attached directly to the bottom of the exposure chamber (chamber air) or placed near the entrance of the chamber (background air) as described above. Backup PUF plugs were installed behind the primary PUF in the sampling cartridges to assess for contaminant breakthrough. To determine background 
levels of test chemicals, the air entering the growth chamber was sampled at $1.8 \mathrm{~m}^{3} \mathrm{~h}^{-1}$ collected at 24 hour intervals. The exposure chamber air was sampled at $4.8 \mathrm{~m}^{3} \mathrm{~h}^{-1}$ collected at 12 hour intervals. After collection, the cartridges were labeled, wrapped in foil, sealed in plastic and stored at $-20^{\circ}$ until work up. All samples were spiked with a deuterated isotope dilution standard and extracted in DCM using the flow-through extraction method previously described (39).

Plant sampling and workup. Leaf samples (ca. $5 \mathrm{~g}$ each) were collected from random locations within the chamber and transferred directly to $50 \mathrm{ml}$ amber bottles with Teflon lined caps. Duplicate or triplicate samples were collected at several time points to assess leaf-to-leaf variability and to confirm mixing within the chamber. The bottles were labeled, sealed in plastic and stored at $-20^{\circ}$ until work up. Prior to extraction, the samples were spiked with deuterated isotope dilution standards. Each sample was extracted twice by one hour sonication in fifty milliliters of hexane. Although dichloromethane has a slightly higher extraction efficiency for PAHs in vegetation samples, the hexane extract was used in this work because the extract contained less plant pigment and water and was easier to cleanup prior to analysis. The hexane extracts were filtered through a $0.45 \mu \mathrm{m}$ Teflon coated filter along with several sample rinses into a flask containing a small amount of anhydrous $\mathrm{Na}_{2} \mathrm{SO}_{3}$ (drying agent). The extract was then concentrated to $0.5 \mathrm{ml}$, quantitatively transferred to a solid phase extraction cartridge (Waters \#51900 normal phase silica) and eluted with $2.5 \mathrm{ml}$ hexane into a screw top amber vial. Just prior to analysis, the samples were concentrated to dryness and immediately reconstituted in 100 $\mu \mathrm{l}$ DCM containing an appropriate amount of dueterated recovery standard.

Sample Analysis. Both air and plant extracts were analyzed using a Hewlett-Packard Model 5890 Series II Gas Chromatograph (GC) equipped with a Model 7290 autosampler interfaced to a Hewlett-Packard Model 5970A mass selective detector (MSD). The GC was equipped with a split/splitless injector and an electronic pressure controller. The injector was run in the splitless mode and the electronic pressure controller was programmed for vacuum compensation and constant flow. The GC was equipped with a $30 \mathrm{~m} \times 0.25 \mathrm{~mm}$ i.d. DB-5 fused 
silica capillary column $(0.25 \mu \mathrm{m}$ film thickness; J\&W Scientific $)$. The mobile phase was He with a flow rate of $33.5 \mathrm{~cm} \mathrm{~s}^{-1}$. The temperature program was isothermal at $40{ }^{\circ} \mathrm{C}$ for $5 \mathrm{~min}$. then $10^{\circ}$ $\min ^{-1}$ ramp to $270{ }^{\circ} \mathrm{C}$, isothermal for $5 \mathrm{~min}$. then $10^{\circ} \mathrm{min}^{-1}$ ramp to $310{ }^{\circ} \mathrm{C}$ and isothermal for 4 $\min$. The injector and detector temperatures were $285^{\circ} \mathrm{C}$ and $295^{\circ} \mathrm{C}$, respectively and the injection volume was $2 \mu \mathrm{l}$. The MSD was run in selective ion monitoring (SIM) mode. Each analyte was quantified using the abundance of the relevant target ion and a 5-point calibration curve.

The average recovery for the air samples was $103 \%(\mathrm{n}=45)$ and breakthrough from the primary PUF to the backup cartridge was consistently less than $5 \%$. Standard recoveries of the plant samples ranged from $40 \%$ to $96 \%$ with average recoveries of $77 \%$.

Exposure Scenario. The chamber atmosphere and the plants were conditioned for approximately two days prior to the start of the exposure event by drawing air through PUF plugs into the exposure chamber containing the plant at $4.8 \mathrm{~m}^{3} \mathrm{~h}^{-1}$. The PUF plugs were changed every 12 hours. During the conditioning period, the gas-phase pollutant generator column containing AN, FL and PY was attached to the chamber top plate and fitted with a small sampling cartridge (10 cc luerlock syringe barrel containing PUF adsorbent plug). The generator column was turned on $\left(35^{\circ} \mathrm{C}\right.$ and $16 \mathrm{cc} \mathrm{min}^{-1} \mathrm{~N}_{2}$ flow $)$ and allowed to stabilize for several hours. At least three consecutive samples were collected from the generator column to characterize the pre-exposure source term. The source was also measured at the end of the exposure event and the measurements were averaged to estimate the continuous source strength during the exposure phase. Change in the source from the beginning to the end of the exposure phase was typically less than $5 \%$. The total source during exposure includes both the generated source and background levels of each chemical entering the exposure chamber. The contribution of background levels to the total source were $93 \%, 5 \%, 4 \%$ and $16 \%$ for phenanthrene, anthracene, fluoranthene and pyrene, respectively.

The day/night cycle during the experiment was programmed for 12 hours of light at 20.5 
${ }^{\circ} \mathrm{C}$ and 12 hours dark at $24.5^{\circ} \mathrm{C}$ with a one hour ramp period between each period. The temperature program in the CER compensated for heat generated by the lights to maintain an internal exposure chamber temperature of $24.0 \pm 0.5^{\circ} \mathrm{C}$ throughout the experiment. Relative humidity remained between $50 \%$ and $60 \%$ in the CER. Plants were watered with either tap water or a nutrient solution and inspected daily during the exposure experiment. There were no visible signs of stress.

\section{Results and Discussion}

The two-box mass balance (eqs. 5 and 6) was optimized in three steps using the concentration time series profiles (plant and air) measured in the exposure chamber. First, initial values for the unknowns $\left(K_{p a}, U_{p a}, R_{a}\right.$, and $\left.R_{p}\right)$ were found using a spreadsheet solver routine that minimized the log transformed squared error ( $L S E)$ between the estimated and measured concentrations in both the air and the plant compartments. Next, a probabilistic sensitivity analysis ((40) (41), pp 267-268) was used to identify the model inputs with the greatest influence on the outcome of the optimization routine. Finally, uncertainty associated with the most influential inputs was propagated through the model solution to provide a final estimate for each intermedia transfer factor along with the corresponding experimental error.

The independent variables used in the mass balance are summarized in Table 2. The source strength and starting concentrations for each chemical are reported in Table 3 . The postexposure source to the air compartment was estimated from the steady state concentration in an empty chamber running with the generator column turned off and PUF plugs installed at the chamber inlets. The post-exposure source accounts for small levels of breakthrough at the PUF inlet cartridges and any leakage that may occur around the chamber base. Starting concentrations in the plant and air were from replicate measurements collected at the end of the conditioning phase.

The concentration time series profiles along with resulting curves for air and plant concentrations from the optimized model are illustrated in Figure 2. The curves for each 
chemical were evaluated simultaneously so that a single optimized set of unknowns could be applied to both the air and plant compartments. An improved fit for a given compartment (i.e., time-series profile for PH in air) may be possible but only at the expense of reducing the performance of the model for the other compartment (i.e., PH in the plant). Thus, the results illustrated in fig. 2 are the overall optimization for each chemical of the fully coupled twocompartment model over both the exposure and post-exposure interval time periods.

Probabilistic sensitivity analysis. Replicate measurements collected during the chamber characterization and plant exposure experiments were used to construct log normal distributions for each independent variable in the mass balance model. The shape of the distribution for the source $\left(J_{i}\right)$ was not obvious from the data but a goodness-of-fit test ((42), pp 100-101) indicated that the log normal distribution was adequate. Several other distribution types were tested during the error propagation phase and it was found that the results (not shown) were not strongly influenced by the choice of statistical model (i.e., lognormal, Weibull or triangular) for the source term.

The probabilistic sensitivity analysis was performed by allowing each input in Tables 2 and 3 (excluding the calculated inputs, $t^{\text {end }}$ and $G_{p}$ ) to vary across its assigned distribution (2500 realizations) while all other inputs and the four unknowns were held at their mean and optimized values, respectively. The change in model performance was tracked during the analysis resulting in a distribution of $L S E$ for each variable. The $C V$ of the set of $L S E$ values generated by independently varying each input was used as a surrogate measure of the importance of the particular model input. The relative importance of each input to the model optimization is illustrated in Figure 3.

The source term $\left(J_{1}\right)$ was found to be the main contributor to variance overall with $25 \%$ to $65 \%$ of total variance in $L S E$ due to uncertainty in the exposure source strength. The effective chamber volume, mass of plant in the chamber and starting concentration in the plant also contribute to variance in the optimization for all the chemicals while the post-exposure source 
strength was important only for phenanthrene. The model was also evaluated using an input classification method designed to identify the minimum set of stochastic inputs needed to capture essentially all of the outcome variance in a model (40). The results confirmed that the four inputs (five in the case of phenanthrene) identified in the probabilistic sensitivity analysis contribute essentially all of the variance in the optimization. The starting concentration in air, flow rate through the chamber, leaf area density and the mass density of vegetation did not significantly influence the optimization for any of the chemicals and were therefore excluded (i.e., held constant at their mean value) during the error propagation step.

Error propagation. To propagate experimental error through the optimization routine, 100 combinations of the most influential variables identified in the probabilistic sensitivity analysis were randomly drawn from the assigned distributions using a Latin Hypercube sampling routine. Each combination of inputs was entered in eqs 5 and 6 and the model was optimized as described earlier. The set of optimized values for $K_{p a}, U_{p a}, R_{a}$ and $R_{p}(\mathrm{n}=100$ for each) provide an estimate of the experimental error reported as $C V$ along with the intermedia transfer factors in Table 4.

The sensitivity analysis described above identified the inputs that were important to the overall performance of the model. We extended the sensitivity analysis using the data from the error propagation to identify relationships between the model inputs and each optimized transfer factor. The correlation coefficients listed in Table 5 describe the strength of linear relationship between the uncertain values used to characterize the system and the optimized transfer factors for each chemical. The coefficients that are significant at the 5\% level are highlighted in bold.

The plant-air partition coefficient, $K_{p a}$, is one of the more studied transfer factors for vegetation and as a result there are several estimation methods available. Estimates of $K_{p a}$ using four different estimation models and typical plant characteristics identified by McLachlan ((43), pp 118-120) are within $\sim \pm 10 \%$ of the $K_{p a}$ values derived for the four PAHs using the exposure chamber data and two-box mass balance model. The range of optimized values for $K_{p a}$ in Table 4 
(reported as $\pm C V$ ) is a reflection of how robust the optimization is to changes in the uncertain model inputs. It is important to note that the actual uncertainty in $K_{p a}$ is expected to be much greater than the experimental error reported in Table 4. Interspecies variability alone can result in $K_{p a}$ values that differ by up to an order of magnitude ((43), page 121). Replicate experiments with different plants and conditions are needed to fully characterize uncertainty and variability in the transfer factors.

The results in Table 5 show that the estimate of $K_{p a}$ for PY and FL are primarily dependent on the source strength during exposure and the effective volume of the chamber. The results for $\mathrm{AN}$, which is the most reactive of the four chemicals, show that the estimate of $K_{p a}$ is influenced by the volume and mass of the two compartments indicating that the loss side of the mass balance is important. For $\mathrm{PH}$, the one chemical in the analysis that was not included in the generator cartridge, none of the inputs strongly influential the estimate of $K_{p a}$. This is likely due to the fact that the air and plant concentrations were close to steady state during most of the experiment and that variation in the source term was small relative to the chemicals that were included in the generator column.

The overall mass-transfer coefficient across the plant/air interface is typically considered a function of diffusive mass-transfer in the boundary layers on either side of the interface (44). The general relationship is $U_{p a}=\left(1 / U_{a}+1 / K_{p a} U_{p}\right)^{-1}$ where $U_{a}$ and $U_{p}$ are the air and plant side mass-transfer coefficients, respectively. $U_{a}$ can be estimated from the boundary layer conductance of water vapor over the leaf $(45)$ and $U_{p}$ has been related to the permeance of aqueous phase chemical through isolated cuticle (13). Direct measurements of $U_{p a}$ for intact plants are generally lacking. Bakker (46) recently summarized a number of plant-air mass transfer coefficients that were estimated from elimination rate constants from six different studies and the values ranged from $0.3-80 \mathrm{~m} \mathrm{~h}^{-1}$. The values of $U_{p a}$ determined in this study range from $1.8 \mathrm{~m} \mathrm{~h}^{-1}$ for $\mathrm{PH}$ to $5.0 \mathrm{~m} \mathrm{~h}^{-1}$ for $\mathrm{FL}$. Although the results from this study fall within the range of values derived from elimination or clearance rates, it is important to note that the 
combined use of air and plant data with the two-box model provides a means to separate out loss by diffusion and loss by chemical transformation. For more reactive chemicals this may lead to differences in estimates of $U_{p a}$ but it is unclear how significant these differences might be. Estimates of $U_{p a}$ based only on the clearance data in the plant compartment from this study differed from the values estimated using the coupled air/plant model by $40 \%-65 \%$.

The precision of the estimate of $U_{p a}$ is lower than that of the partition coefficients but the results are still relatively robust to uncertainty in model inputs. With the exception of $\mathrm{PH}$, nearly all of the uncertain inputs influence the estimate of $U_{p a}$. For PH, it seems that only uncertainty in the mass of the plant compartment $\left(M_{p}\right)$, which is used to estimate the interfacial area between the air and plant, influences the optimization of the mass transfer rate. Again, this may be due to the fact that the source term for PH did not vary as much over the course of the exposure event compared to the chemicals that were included in the generator column.

The reported degradation half-life (h) in air for the PAHs included in this study are 2.01$20.1(\mathrm{PH}), 0.58-1.7(\mathrm{AN}), 2.02-20.2(\mathrm{FL})$ and 0.68-2.04 (PY) (47). In contrast, the values measured under the conditions of this study are non-detect, 2.5, 9.2 and $25 \mathrm{~h}$ for PH, AN, FL and PY, respectively. The values from this study are generally at the high end of the range of reported values, which may be related to a lower-than-outdoor light intensity inside the exposure chamber. Although a number of measurements and methods are available for estimating the degradation half-life of PAHs in air, estimates of the reaction half-life in plants are lacking. The estimated half-life for reaction in the plant compartment given the conditions of this study range from approximately $110 \mathrm{~h}$ for PY and $150 \mathrm{~h}$ for AN to $17 \mathrm{~d}$ for PH and FL.

The precision of the optimized reaction rates is relatively low compared to the other transfer factors indicating that the solution field for $R_{a}$ and $R_{p}$ is relatively flat. The optimization of the reaction rates in the air compartment is generally controlled by the volume normalized source strength to air, which is a function of both $V_{c}$ and $J_{l}$. The reaction rate in the plant is influenced mainly by the mass of vegetation, which is used along with the plant density to 
calculate the volume of the plant compartment.

Improving the control and measurement of some of the exposure characteristics, particularly those related to the source to air and the volume of plant, will lead to increased confidence in the estimates of the reaction rates. However, the combined use of models and data provides a robust method for simultaneously estimating multiple transfer factors that influence the fate of pollutants in the air/plant system.

\section{Acknowledgements}

The authors were supported in part by the U.S. Environmental Protection Agency funding of research at the Lawrence Berkeley National Laboratory through the U.S. Department of Energy under Contract Grant No. DE-AC03-76SF00098. Environmental Protection Agency funding was provided by the National Exposure Research Laboratory through Interagency Agreement \#DW988-38190-01-0. The authors' efforts were also supported in part under the auspices of the Risk

Sciences Program at the University of California, Davis where funding was provided by the State of California through the Cal-EPA Department of Toxic Substances Control (DTSC) by Contract Agreement 92-T0105 
Bibliography

(1) Nash, R. G. In Pesticides in soil and water; Soil Science Society of America Inc.: Madison, 1974, pp 257-313.

(2) Buckley, E. H. Science 1982, 216, 520.

(3) Whicker, F. W.; Kirchner, T. B. Health Physics 1987, 52, 717.

(4) Calamari, D.; Vighi, M.; Bacci, E. Chemosphere 1987, 16, 2359.

(5) Paterson, S.; Mackay, D. In Pollutant transport: modeling and field measurements; Allen, D. T., Cohen, Y., Kaplan, I. R., Eds.; Plenum Press: New York, 1989, pp 283-292.

(6) Trapp, S.; Matthies, M.; Scheunert, I.; Topp, E. M. Environ. Sci. Technol. 1990, 24, 1246.

(7) Paterson, S.; Mackay, D.; Gladman, A. Chemosphere 1991, 23, 539.

(8) Paterson, S.; Mackay, D.; McFarlane, C. Environ. Sci. Technol. 1994, 28, 2259.

(9) Trapp, S.; McFarlane, C.; Matthies, M. Environ. Tox. Chem. 1994, 13, 413.

(10) Hauk, H.; Umlauf, G.; McLachlan, M. S. Environ. Sci. Technol. 1994, $28,2372$.

(11) Tolls, J.; McLachlan, M. S. Environ. Sci. Technol. 1994, 28, 159.

(12) Trapp, S.; Matthies, M. Environ. Sci. Technol. 1995, 29, 2333-2338.

(13) Riederer, M. In Plant Contamination, Modeling and Simulation of Organic Chemical Processes; Trapp, S., McFarlane, J., Eds.; Lewis Publishers: Boca Raton, 1995, pp 153190.

(14) Hung, H.; Mackay, D. Chemosphere 1997, 35, 959.

(15) Welsch-Pausch, K.; McLachlan, M. S.; Umlauf, G. Environ. Sci. Technol. 1995, 29, 1090.

(16) Simonich, S. L.; Hites, R. A. Environ. Sci. Technol. 1994, $28,939$. 
(17) Bohme, F.; K, W.-P.; M.S., M. Environ. Sci. Technol. 1999, 33, 1805.

(18) Thomas, G.; Sweetman, A. J.; Ockenden, W. A.; Mackay, D.; Jones, K. C. Environ. Sci. Technol. 1998, 32, 936.

(19) Thomas, G. O.; Smith, K. E. C.; Sweetman, A. J.; Jones, K. C. Environ. Poll. 1998, 102, 119.

(20) Hiatt, M. H. Analytical Chemistry 1998, 70, 851.

(21) Bacci, E.; Calamari, D.; Gaggi, C.; Vighi, M. Environ. Sci. Technol. 1990, 24, 885.

(22) Schroll, S.; Scheunert, I. Chemosphere 1992, 24, 97.

(23) McCrady, J. K.; Maggard, S. P. Environ. Sci. Technol. 1993, 27, 343.

(24) Paterson, S.; Mackay, D.; Bacci, E.; Calamari, D. Environ. Sci. Technol. 1991, 25, 866.

(25) McFarlane, C. J.; Pfleeger, T. Journal of Environmental Quality 1987, 16, 361.

(26) Rogers, H. H.; Geffries, H. E.; Stahel, E. P.; Heck, W. W.; Ripperton, L. A.;

Witherspoon, A. M. Journal of air pollution control association 1977, 27, 1192.

(27) Heagle, A. S.; Philbeck, R. B.; Ferrell, R. E.; Heck, W. W. Journal of Environmental Quality 1989, 18, 361.

(28) Jeffries, H. E.; Rogers, H. H.; Stahel, E. P. Sci. Biol. Ser. 1976, 2, 180.

(29) Heck, W. W.; Philbeck, R. B.; Dunning, J. A. ; A continuous stirred tank reactor (CSTR) system for exposing plants to gaseous air contaminantsU.S. Report Number ARS-S-181; U.S. Department of Agriculture: 1978.

(30) Bacci, E.; Cerejeira, M. J.; Gaggi, C.; Chemello, G.; Calamari, D.; Vighi, M. Chemosphere 1990, 21, 525.

(31) Briggs, G. G.; Bromilow, R. H.; Evans, A. A. Pesticide Science 1982, 13, 495.

(32) Schwarzenbach, R. P.; Gschwend, P. M.; Imboden, D. M. Environmental Organic Chemistry; Wiley Intersciences: New York, 1993. 
(33) Maddalena, R. Doctoral Dissertation, University of California at Davis, Davis, CA, 1998.

(34) McGarvey, L. J.; Shorten, C. V. American Industrial Hygiene Association Journal 2000, 61,375 .

(35) Van_Loy, M. D.; Riley, W. J.; Daisey, J. M.; Nazaroff, W. W. Environ. Sci. Technol. $2001,35,560$.

(36) Pratt, W. B. In Principles of Drug Action: The Basis of Pharmacology; Pratt, W. B., Taylor, P., Eds.; Churchill Livingstone: New York, 1990, pp 836.

(37) USEPA ; Office of Air and Radiation Office of Air Quality Planning and Standards: Research Triangle Park, NC 2771, 2000.

(38) McCrady, J. K. Chemosphere 1994, 28, 207.

(39) Maddalena, R. L.; McKone, T. E.; Kado, N. Y. Atmospheric Environment 1998, 32, 2497.

(40) Maddalena, R. L.; McKone, T. E.; Hsieh, D. P. H.; Geng, S. Stochastic Environmental Research and Risk Assessment 2001, 15, 1.

(41) Cullen, A.; Frey, C. H. Probabilistic Techniques in Exposure Assessment: A Handbook for Dealing with Variability and Uncertainty in Models and Inputs; Plenum Press: New York, 1999.

(42) Stephens, M. A. In Goodness of fit techniques; D'Agostino, R. B., Stephens, M. A., Eds.; Marcel Dekker, Inc.: New York, 1986; Vol. 68, pp 100-101.

(43) McLachlan, M. S. In Handbook of Property Estimation Methods for Chemicals;

Boethling, R. E., Mackay, D., Eds.; Lewis Publishers: New York, 2000, pp 481.

(44) Mackay, D. Multimedia Environmental Models, the Fugacity Approach; Lewis Publishers: Chelsea, MI, 1991.

(45) Nobel, P. S. Physiocochemical \& Environmental Plant Physiology, second ed.; Academic Press: New York, 1999. 
(46) Bakker, M. Doctoral Thesis, Utrecht University, Utrecht, 2000.

(47) Mackay, D.; Shiu, W. Y.; Ma, C. Illustrated Handbook of Physical-Chemical Properties And Environmental Fate for Organic Chemicals; Lewis Publishers: Boca Raton, 19921995. 
Table 1. Variables used in the dynamic solution of the two-compartment mass balance model

\section{Overall rate constants $\left(\mathrm{d}^{-1}\right)$}

$$
\begin{array}{cc}
k_{11}=\left(\frac{R_{a} V_{c}+f+U_{p a} A_{p a}}{V_{c}}\right) & k_{12}=\left(\frac{U_{p a} A_{p a}}{K_{p a} V_{c}}\right) \\
k_{21}=\left(\frac{U_{p a} A_{p a}}{V_{p}}\right) & k_{22}=\left(\frac{U_{p a} A_{p a} / K_{p a}+R_{p} V_{p}+G_{p} V_{p}}{V_{p}}\right)
\end{array}
$$

$\underline{\text { Eigenvalues in eqs } 5 \text { and } 6}$

$$
\begin{gathered}
g_{1}=0.5 \times\left(k_{11}+k_{22}+g g_{12}\right) \quad g_{2}=0.5 \times\left(k_{11}+k_{22}-g g_{12}\right) \\
g g_{12}=\sqrt{\left(k_{11}-k_{22}\right)^{2}+4 k_{12} k_{21}}
\end{gathered}
$$


Table 2. Summary of input values used in mass balance

\begin{tabular}{lccc}
\hline Description and Units & Symbol & Value & $C V$ \\
\hline air flow through chamber $\left(\mathrm{m}^{3} \mathrm{~d}^{-1}\right)$ & $f$ & 115.2 & 0.05 \\
effective volume of chamber $\left(\mathrm{m}^{3}\right)$ & $V_{c}$ & \multicolumn{2}{c}{ See note ${ }^{a}$} \\
mass of vegetation $\left(\mathrm{kg}_{\mathrm{fresh}}\right)$ & $M_{p}$ & 0.40 & 0.10 \\
fresh bulk density of vegetation $\left(\mathrm{kg} \mathrm{m}^{-3}\right)$ & $\rho_{p}$ & 713 & 0.04 \\
leaf area density $\left(\mathrm{m}^{2}{ }_{\text {one-sided leaf }} \mathrm{kg}^{-1}\right.$ fresh leaf $)$ & $L A D$ & 4.23 & 0.09 \\
volume of vegetation in chamber $\left(\mathrm{m}^{3}\right)$ & $V_{p}$ & $M_{p} / \rho_{p}$ & - \\
surface area of vegetation $\left(\mathrm{m}^{2}{ }_{\text {two-sided leaf }}\right)$ & $A_{p a}$ & $2 \times L A D \times M_{p}$ & - \\
end of exposure time $(\mathrm{d})$ & $t^{e n d}$ & 6.9 & - \\
growth dilution rate $\left(\mathrm{d}^{-1}\right)^{b}$ & $G_{p}$ & 0 & -
\end{tabular}

${ }^{\bar{a}}$ The actual volume of the chamber is $0.45 \mathrm{~m}^{3}$. Chemical specific values for $V_{c}$ were discussed earlier and illustrated in Figure 1.

${ }^{b}$ Growth dilution rate is assumed negligible over the 11 day experiment. 
Table 3. Chemical specific source terms and starting concentrations $( \pm C V)$

\begin{tabular}{ccccc}
\hline & PH & AN & FL & PY \\
\hline Exposure source, $\left(\mathrm{ng} \mathrm{m}^{-3} \mathrm{~d}^{-1}\right)$ & $77 \pm 0.23$ & $114 \pm 0.25$ & $36 \pm 0.25$ & $14 \pm 0.11$ \\
$J_{1}^{t=0}$ & & & & \\
Post-exposure Source, $\left(\mathrm{ng} \mathrm{m}^{-3} \mathrm{~d}^{-1}\right)$ & $20 \pm 0.36$ & $0.97 \pm 0.59$ & $0.79 \pm 0.41$ & $0.64 \pm 1.02$ \\
$J_{1}^{t=e n d}$ & & & & \\
Starting concentration in air, $\left(\mathrm{ng} \mathrm{m}^{-3}\right)$ & $2.78 \pm 0.37$ & $0.16 \pm 0.32$ & $0.53 \pm 0.32$ & $0.45 \pm 0.36$ \\
$y_{1}^{t=0}$ & & & & \\
Starting concentration in plant, $\left(\mathrm{mg} \mathrm{m}^{-3}\right)$ & $1.14 \pm 0.27$ & $0.05 \pm 0.33$ & $0.22 \pm 0.33$ & $0.05 \pm 0.89$ \\
$y_{2}^{t=0}$ & & & & \\
\hline
\end{tabular}


Table 4. Measured transfer factors $\left( \pm C V^{a}\right)$ for gas-phase PAH and Capsicum annuum

\begin{tabular}{ccccc}
\hline & PH & AN & FL & PY \\
\hline Log Plant/air partition coefficient & $5.71 \pm 0.01$ & $5.73 \pm 0.02$ & $6.02 \pm 0.01$ & $6.21 \pm 0.01$ \\
$\log K_{p a}$ & & & & \\
Overall mass transfer rate $\left(\mathrm{m} \mathrm{d}^{-1}\right)$ & $42 \pm 0.15$ & $52 \pm 0.15$ & $119 \pm 0.13$ & $105 \pm 0.12$ \\
$\quad U_{p a}$ & & & & \\
Loss rate in chamber atmosphere $\left(\mathrm{d}^{-1}\right)$ & 0 & $6.6 \pm 1.20$ & $1.8 \pm 1.24$ & $0.66 \pm 2.24$ \\
$\quad R_{a}$ & & & & \\
Loss rate in plant $\left(\mathrm{d}^{-1}\right)$ & $0.04 \pm 1.10$ & $0.11 \pm 1.06$ & $0.04 \pm 1.86$ & $0.15 \pm 0.44$ \\
$R_{p}$ & & & & \\
\hline
\end{tabular}

${ }^{a}$ The coefficient of variation is based on a set of 100 model optimizations using a range of likely model inputs. See text for details. 
Table 5. Correlation between key inputs and optimized values ${ }^{\mathrm{a}}$

\begin{tabular}{|c|c|c|c|c|c|}
\hline & & PY & FL & AN & $\mathrm{PH}$ \\
\hline \multirow{4}{*}{$K_{p a}$} & $V_{c}$ & 0.43 & 0.28 & 0.21 & -0.01 \\
\hline & $M_{p}$ & 0.23 & 0.14 & 0.40 & -0.04 \\
\hline & $J_{1}^{t=0}$ & -0.63 & -0.24 & -0.19 & 0.04 \\
\hline & $y_{2}^{t=0}$ & -0.01 & -0.07 & -0.19 & -0.13 \\
\hline \multirow{4}{*}{$U_{p a}$} & $V_{c}$ & 0.50 & 0.27 & 0.38 & -0.24 \\
\hline & $M_{p}$ & -0.44 & -0.27 & -0.17 & -0.64 \\
\hline & $J_{1}^{t=0}$ & -0.36 & -0.14 & -0.46 & 0.17 \\
\hline & $y_{2}^{t=0}$ & -0.70 & -0.54 & -0.65 & -0.16 \\
\hline \multirow{4}{*}{$R_{a}$} & $V_{c}$ & -0.39 & -0.34 & -0.41 & $\mathrm{NA}^{\mathrm{b}}$ \\
\hline & $M_{p}$ & -0.16 & -0.06 & -0.02 & NA \\
\hline & $J_{1}^{t=0}$ & 0.86 & 0.83 & 0.72 & NA \\
\hline & $y_{2}^{t=0}$ & -0.07 & 0.08 & -0.04 & NA \\
\hline \multirow{4}{*}{$R_{p}$} & $V_{c}$ & 0.41 & 0.17 & 0.10 & -0.05 \\
\hline & $M_{p}$ & 0.20 & 0.26 & 0.43 & 0.17 \\
\hline & $J_{1}^{t=0}$ & -0.59 & -0.39 & -0.07 & 0.05 \\
\hline & $y_{2}^{t=0}$ & -0.05 & -0.12 & -0.10 & -0.13 \\
\hline
\end{tabular}

a The correlation coefficients that are significant at the 5\% level are highlighted in bold text.

b NA indicates that the reaction rate could not be measured 


\section{Figure Captions:}

Figure 1: Air concentrations measured in exposure chamber (symbol) to estimate chamber effective volume $\left(V_{c}\right)$ shown with optimized model (line) for each test chemical.

Figure 2: Exposure event time series for phenanthrene (a), anthracene (b), fluoranthene (c) and pyrene (d) with air concentrations $(\times)$ plotted in units of $\mathrm{ng} \mathrm{m}^{-3}$ and plant concentrations $(\mathrm{O})$ plotted as $\mathrm{mg} \mathrm{m}^{-3}$ (fresh mass). The optimized model for each compartment is plotted as a dash line for air and a solid line for plant.

Figure 3: Results of probabilistic sensitivity analysis. Symbols are defined in Tables 2 and 3. 

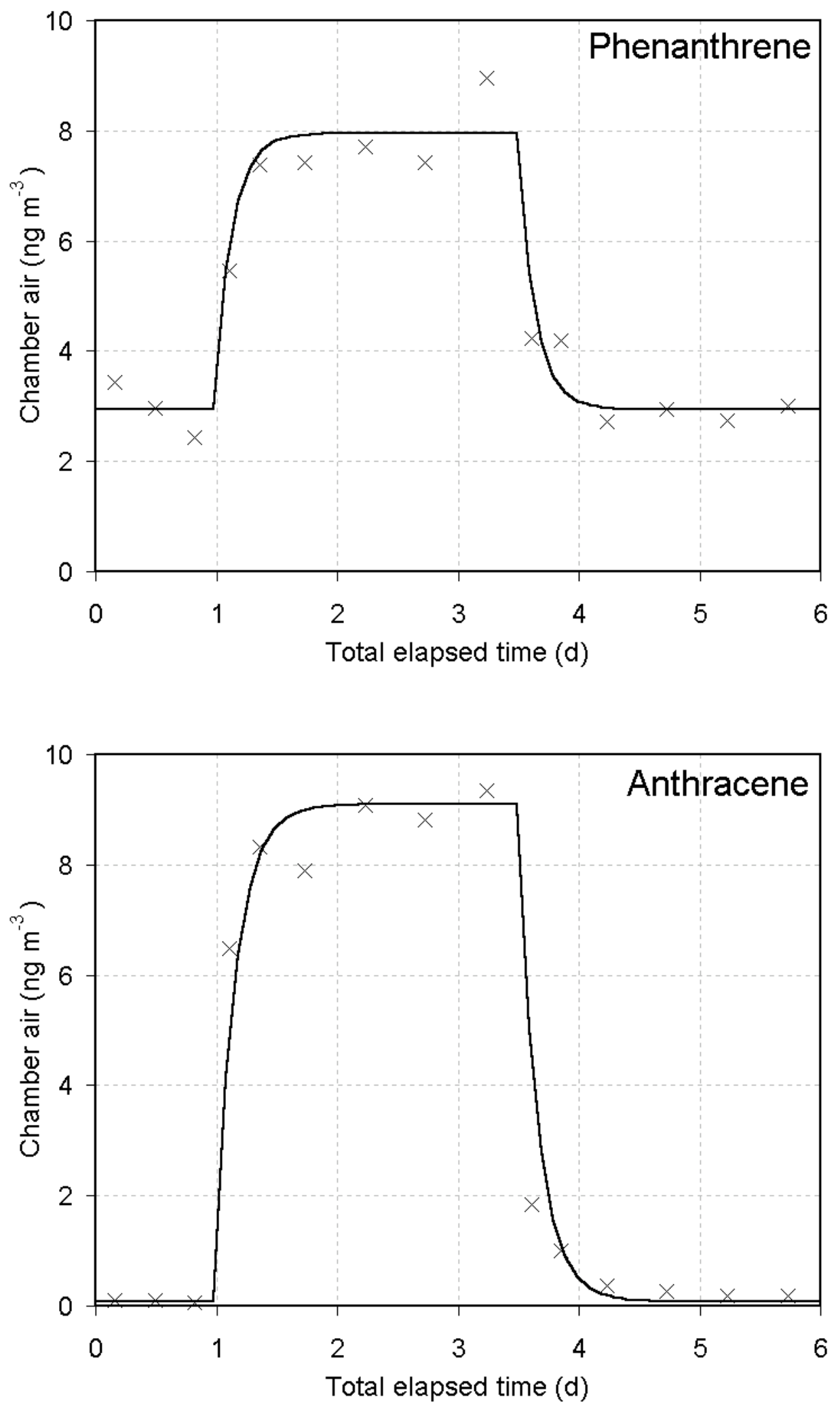

Figure 1 

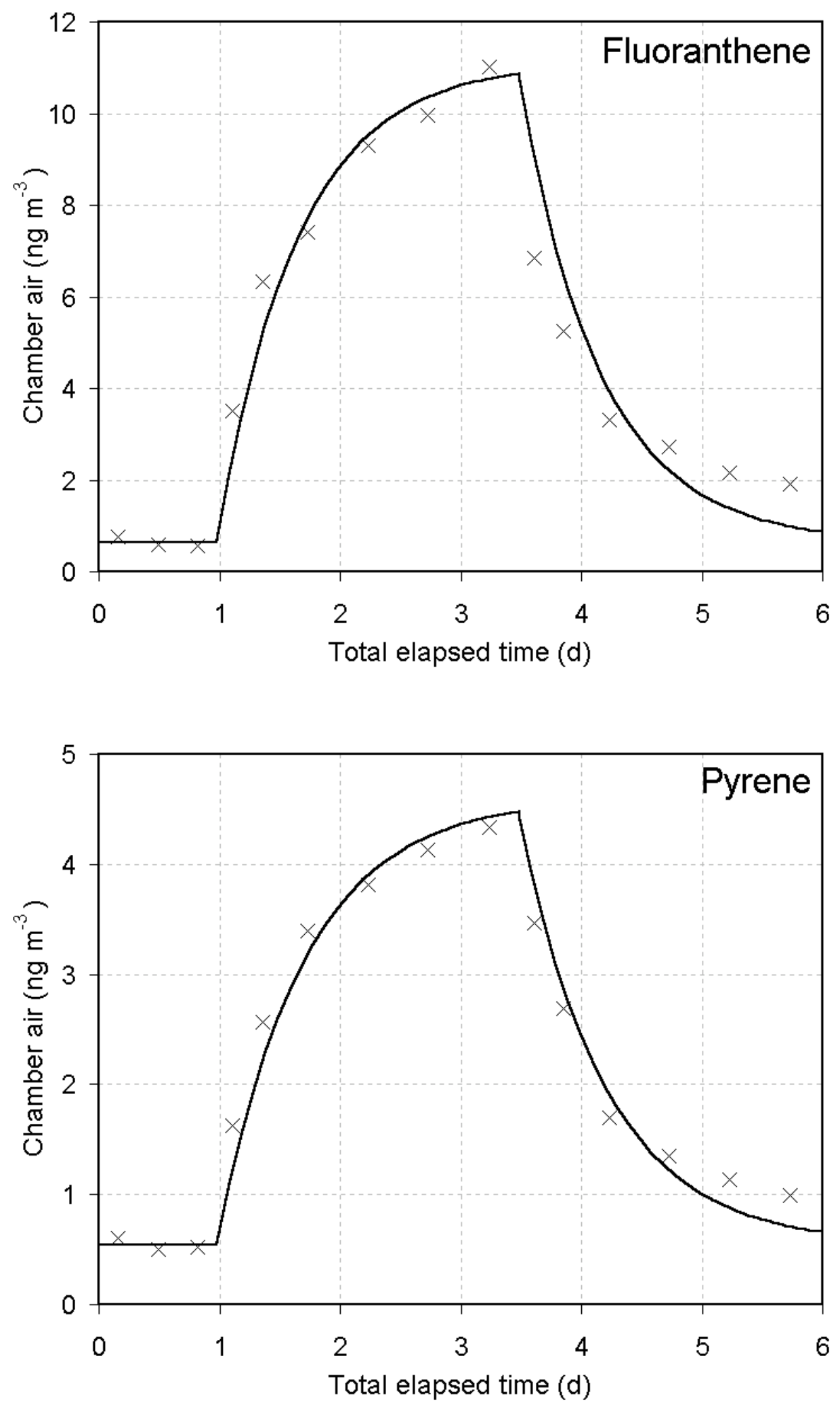

Figure 1 (cont.) 
a.

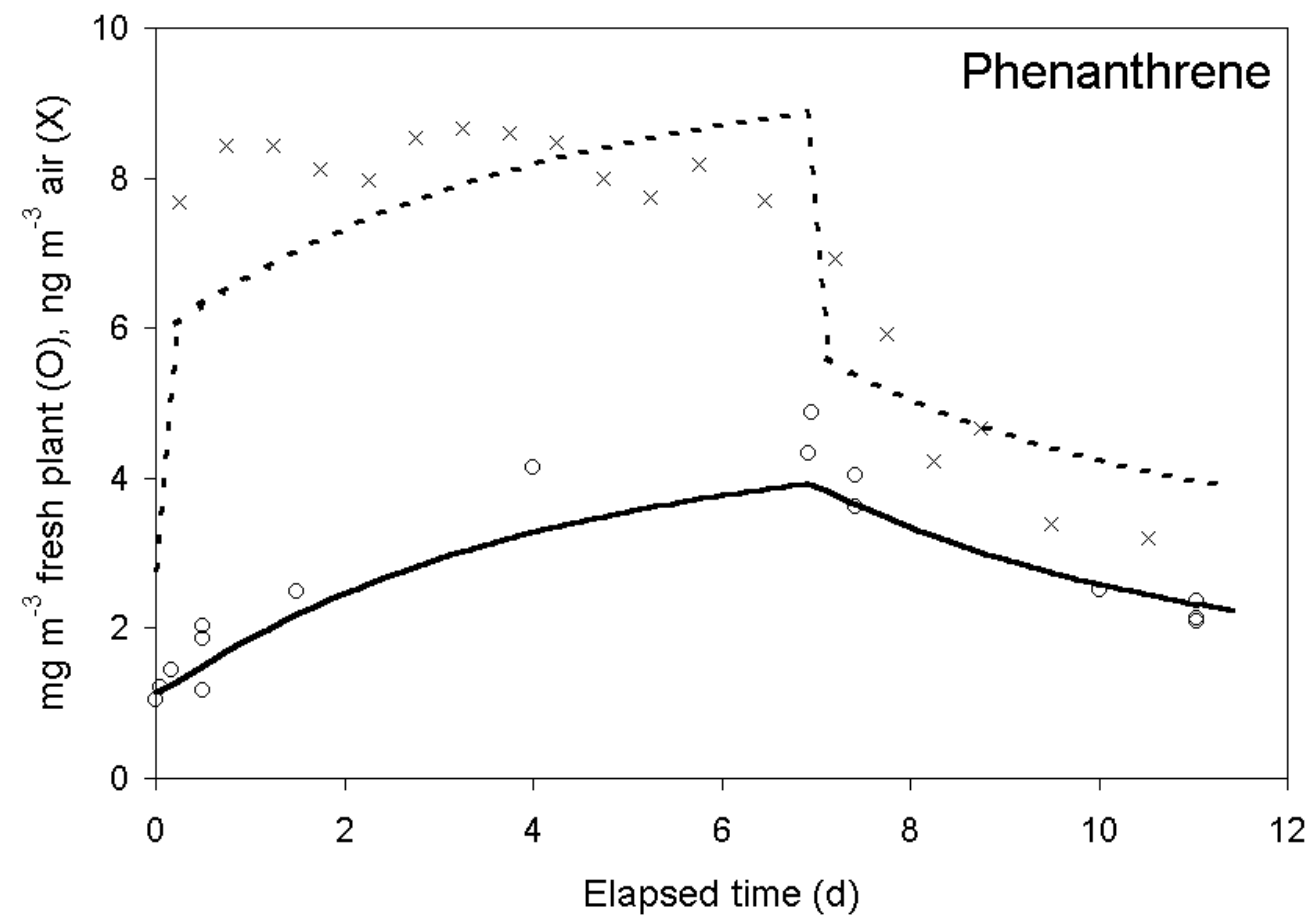

b.

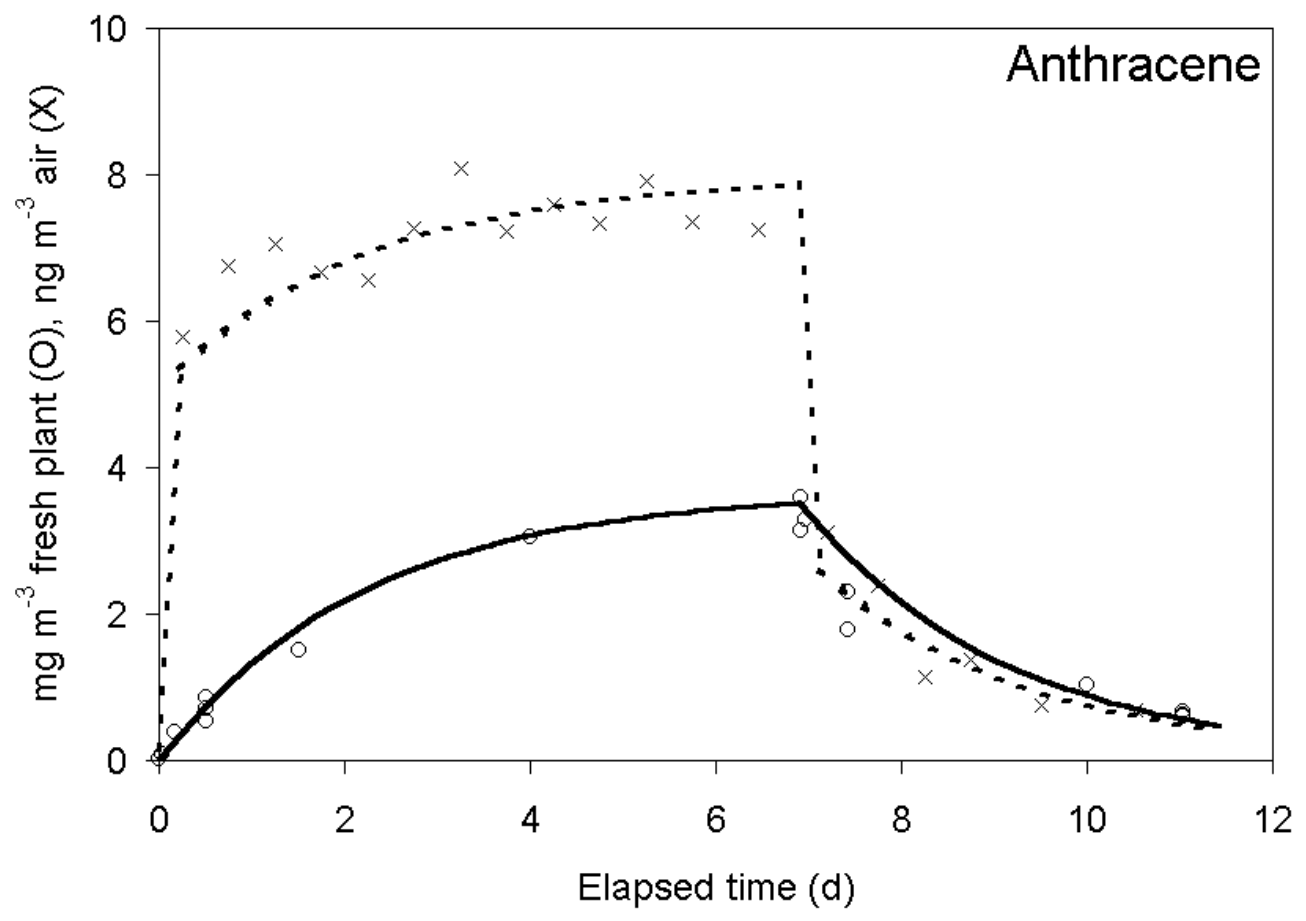

Figure 2 
c.

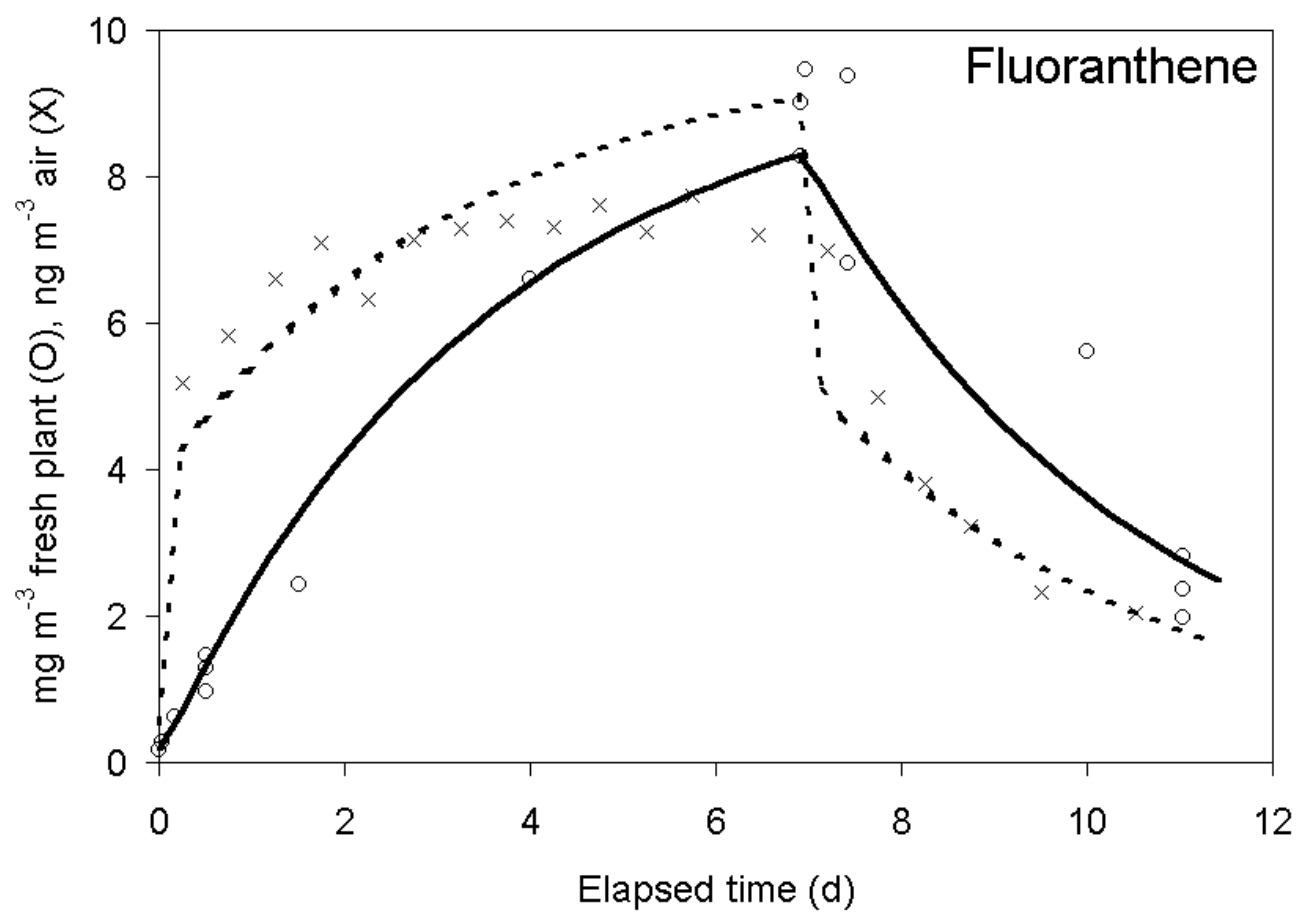

d.

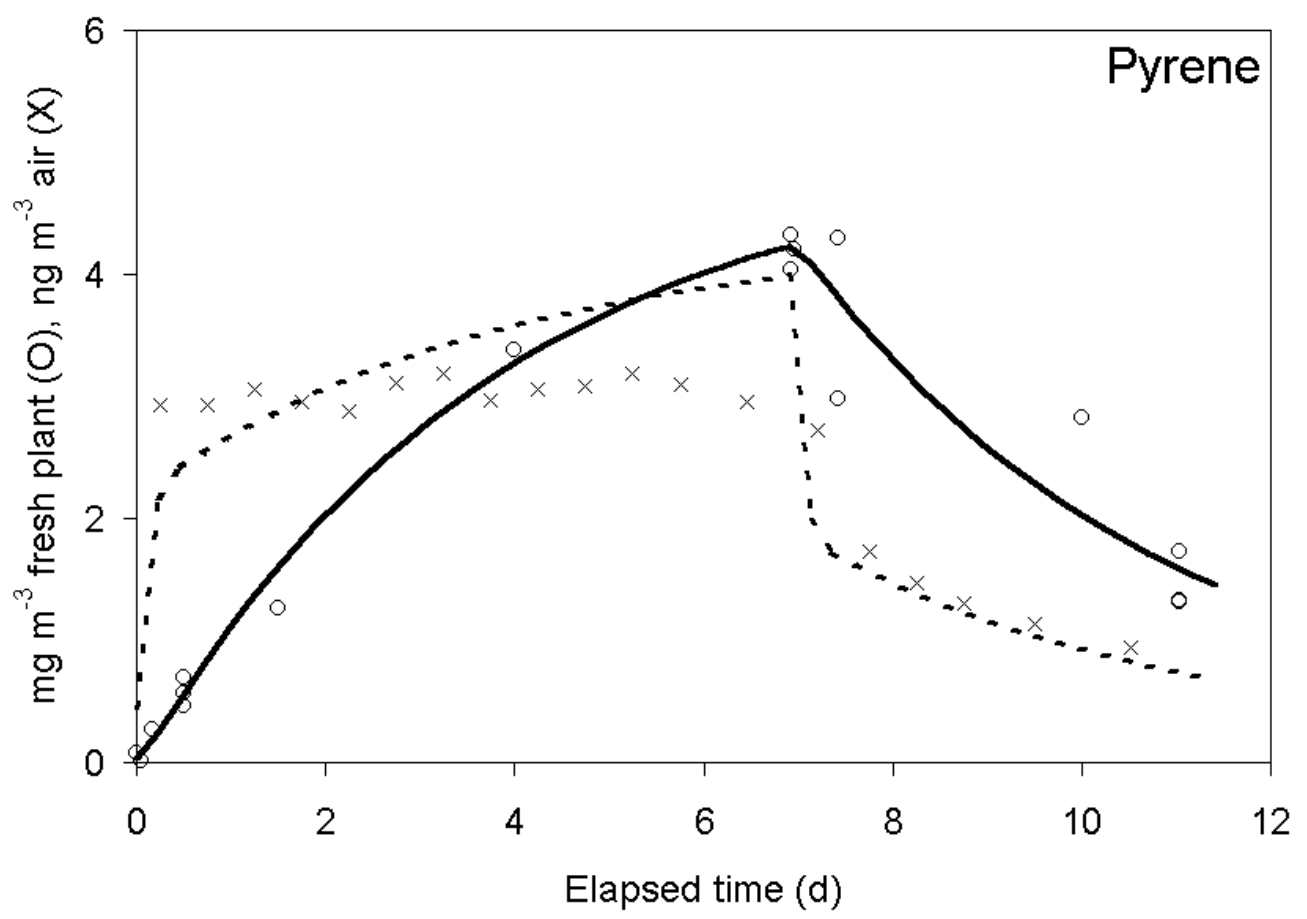

Figure 2 (cont.) 


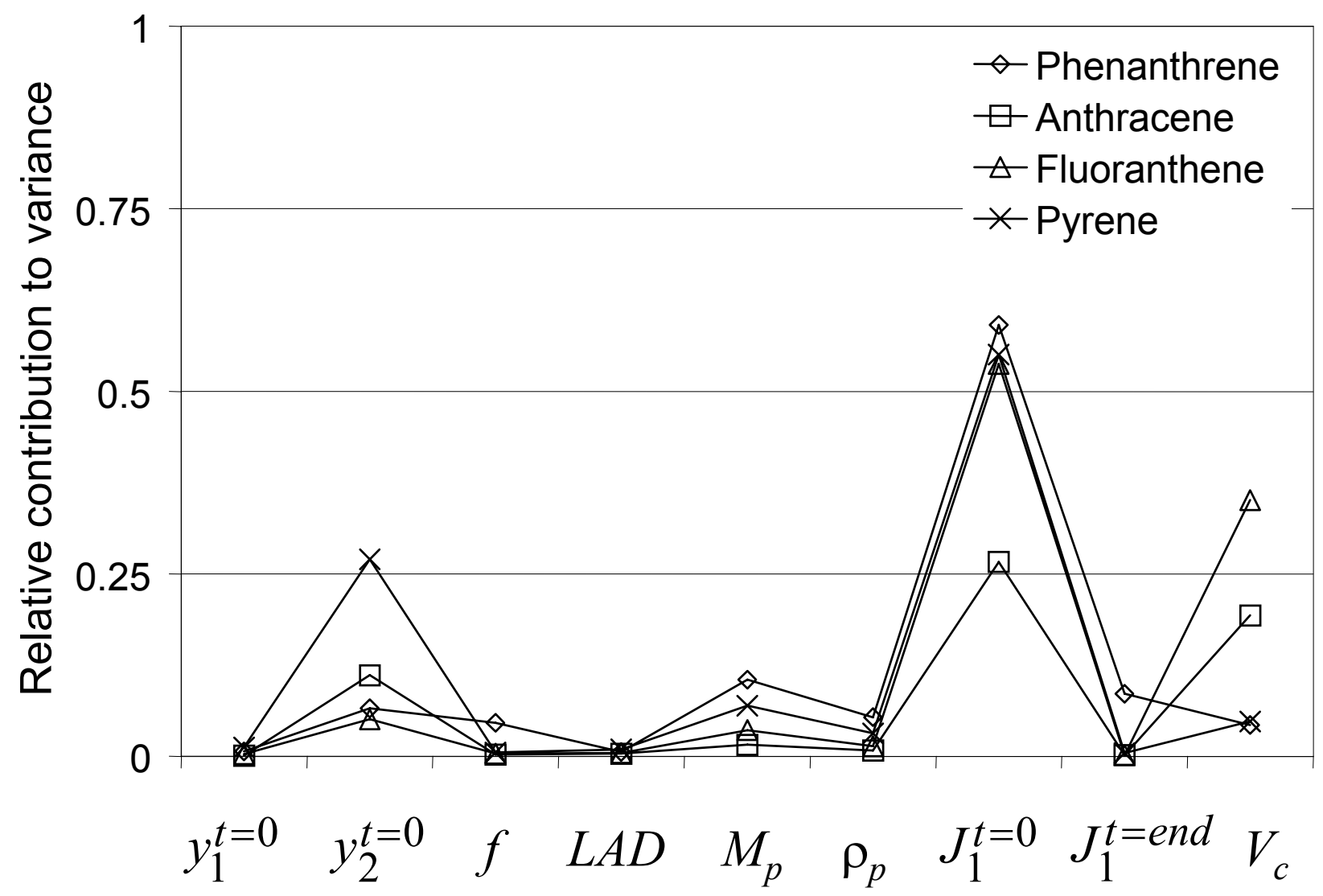

Figure 3 